\title{
Educational Behavior of Children not in Preschool The Case study of Machakos District, Kenya
}

\author{
Kasomo Daniel $^{1,2}$ \\ ${ }^{1}$ Department of Religion, Theology and Philosophy Maseno University, Kenya \\ ${ }^{2}$ Faculty of Psychology, St. James the Elder Theological Seminary, Jacksonville, Florida, USA
}

\begin{abstract}
The research was designed to investigate Activities of Three to Six Year Old Children not in Preschool, The Case study of Machakos District, Kenya in Machakos District in Kenya in East Africa. This research addresses the daily activities of three to six year old children not in preschool in Machakos District, Kenya. The participants comprised 287 children and 287 of their parents/ guardians. The study found that both boys and girls of three to six years of age undertook same activities in their homesteads. However, there were society's stereotyped activities for children of different gender and age. Additionally, the results indicated that playing, which featured as the main children's daily activity, was rated as unimportant by parents/ guardians. Other activities were babysitting, cooking/housework, cultivating, grazing and fetching water and firewood. These activities, which seemingly contribute towards the society's welfare, compromised the education of three to six year old children not in preschools. The results of the study are crucial for setting a plan on how these children can be facilitated to grow and develop to the full. The paper recommends having a parental/ guardian programme geared towards ensuring children's rights to education play and protection.
\end{abstract}

Keywords Child, Preschool, Protectio

\section{Introduction}

The early childhood period from three to six years constitutes an important formative stage in a person's life. Since this period greatly benefits the child, family and community, it requires planning in any society that is responsible for and accountable to its children, who are the future human resource. At the World Education conferences held in Jomtien (1990) and Dakar (2000), children were identified as among the most vulnerable of the world's populations and whose education is crucial to attaining basic educational goals (UNESCO, 1990; UNESCO, 2000). The Jomtien Conference stated that learning begins at birth and that "arrangements involving families, communities or institutional programmes as appropriate to reach all children" be set (Article 5, Par. 8) (UNESCO, 1990). Consequently, Kenya, which is a signatory to the 1989 United Nations Convention on the Rights of the Child, has formulated the Children Act (2001) document forms a major point of reference upon which the Government, families and communities can be held accountable for the children's education, play and protection rights (Children Act 2001, Article 7). Thus, in principle, education is a right for all children in Kenya.

Principles pertaining to the Government's reforms on the

* Corresponding author:

dkasomo@hotmail.com (Kasomo Daniel)

Published online at http://journal.sapub.org/ijap

Copyright (C) 2012 Scientific \& Academic Publishing. All Rights Reserved child's education are stipulated in the Education Sessional Paper No. 1, 2005. The document presents the Government's Legal Strategies and Policies regarding children's right to quality, relevant and lifelong education. This is because preschool education for preparing children for the free and compulsory primary education fits Kenya's educational structure. However, only 900,000 (35\%)n children are accessing preschool education (Educational Sessional Paper No. 1, 2005). It is important to know what happens to the $65 \%$ of Kenyan children not enrolled in preschool. This scenario demands investigation of activities that these children do on a daily basis. Studies have given some reasons why some children are not in school. For instance, Garcia and Lukshin (2001) in their research on the relationship between women empowerment and children's access to education lay emphasis on the way some children cannot make it to organized educational programmes because their parents are poor. In addition, Swadener and Kabiru (1995) have suggested that some children in Kenya are not in preschool because families do not understand the significance of preschool education.

Machakos District, the area of this study, is an example of those districts in Kenya whose over $60 \%$ of three to six year old children have not enrolled in preschool (Table 1). According to Machakos District Development Plan 1997 2001 (Republic of Kenya, 1997), the district is marginalized and vulnerable to frequent droughts which make the population to be highly impoverished. Poverty becomes a condition Machakos people have to live with as they address the 
educational needs of their children. Therefore, the purpose of the study was to describe the kind of activities Machakos District children not in preschool are involved in daily so as to form a basis for advocating for measures that the Government and parents can take to guarantee children's rights to education, play and protection.

Table 1. Three to six year old children in and out in preschool in Machakos District

\begin{tabular}{|c|c|c|}
\hline Year & No. of Preschool & No. not in Preschool \\
\hline 2009 & $7991(36 \%)$ & $14222(64 \%)$ \\
\hline 2010 & $7869(36 \%)$ & $14098(64 \%)$ \\
\hline 2011 & $7174(32 \%)$ & $15281(68 \%)$ \\
\hline
\end{tabular}

Source: Machakos District Office

\section{Objectives}

The objectives of the study were to:-

-. Examine the nature of activities three to six year old children not in preschools are involved in on a daily basis in Machakos District.

- Explain the relationship between the activities these children are involved in and their background characteristics.

- Assess the relationship between the children's activities and the background characteristics of the parents/guardians.

\section{Significance of the Study}

Three to six year old children not in preschool have a right to education (Convention on the Rights of the Child, Articles 28 and 29; Children Act 2001, Article 7). What these children do on a daily basis raises concerns for policy, advocacy and legislation regarding facilitating their full growth and development. The information becomes crucial in guiding the society to plan for these children's education for a better future. Edwards (1996:820) writes:

Childhood is a once - and - for - all biological window of opportunity for investment in human beings. Losses incurred can never be made good and a failure to support children will have a permanent effect on society's capacity to develop.

These children not in preschool have to live now and in the future. Their lack of education cannot be taken an inevitable because the prosperity of the entire country depends on the kind of investment that is made in children.

The advocacy and lobbying target parents and the government who have the moral obligation to ensure that these children enjoy the benefit of their right to education from early childhood. It is important to involve them because what children do on a daily basis needs to be coordinated, directed and facilitated to enhance some holistic education. This study generated field based data that would become the Mbeere District's audit and census of children's activities. In addition, the kind of preparation for primary education these children receive is different from that of those children who attend preschool. This raises the need to support the training of primary school teachers so that they can cope with the different types of children registering for standard one.

\section{Methodology}

The study employed cross sectional survey research design in terms of what is happening presently to the three to six year old children not in preschool in Machakos. This design enabled the understanding of the pattern of behavior among children of different ages and gender. Both stratified and purposive sampling techniques were employed to identify the participants in the investigation. The sample was drawn from Kaani, Katelembo, Mitaboni and Katoloni, the four administrative divisions of Machakos District. The local Chiefs helped to identify 287 homesteads known to have children not attending preschool education. Thus, there were 287 children and 287 parents/ guardians identified to take part in the study.

An open ended interview schedule was administered to the 287 parents. Items were read to them and their responses were recorded, and where necessary Kikamba/local language was used as the medium of communication. At the same time, the activities of the participating child were observed and recorded even in the shambas and herding areas which were not far from their homesteads. Each respondent to the interview schedule was given an identification number (Case 1 to Case 287). The same was done with the 287 observed children. Descriptive statistics in terms of frequencies and percentages were calculated with regard to the number of variables under study. The dependent variable was the children's activities, while the children and parent/guardians background characteristics were the independent variables. A pie chart and bar graphs were used to present the findings. For substantiation purposes, reference to some direct content analysis of the responses was made.

\section{Results}

Figure 1 shows the children's main daily activities observed and confirmed by their parents/guardians. The common children's daily activities were playing $(34 \%, \mathrm{n}=$ $241)$, Cooking/ housework $(16 \%, \mathrm{n}=111)$ and baby sitting $(14 \%, n=98)$.

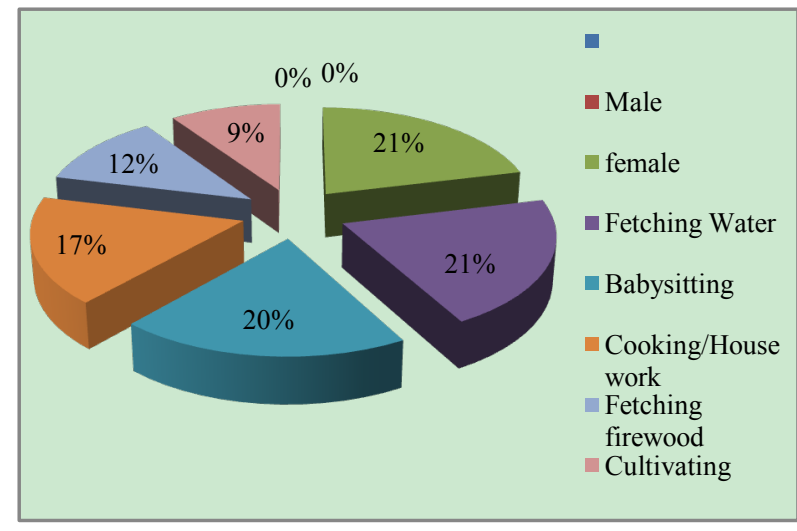

Figure 1. Daily activities of children 
Playing was the main activity for both male and female children, although male children $(51 \%, \mathrm{n}=123)$ tended to dominate, female children were not far off $(49 \%, n=118)$ (Graph 1). In regard to the baby sitting activity, the female child was mostly involved $(60 \%, \mathrm{n}=59)$, while the male child only constituted $40 \%(n=39)$. The same scenario was indicated in the case of cooking/ housework activities were $69 \%(n=76)$ of the female children were involved compared to $31 \%(n=34)$ of the male children.

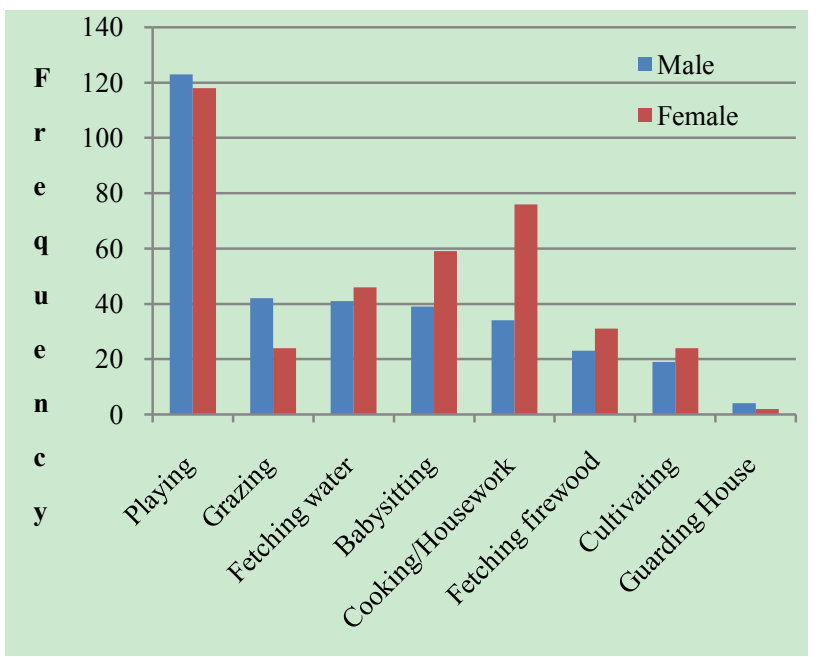

Graph 1. Daily activity of the child by gender

Grazing was more male child oriented, with $64 \%(n=42)$ male children compared to $36 \%(n=24)$ female children. Fetching firewood was done by both the female and the male child even though the female child tended to be slightly more involved $(57 \%, \mathrm{n}=31)$ than the male child $(43 \%, \mathrm{n}=23)$. There was also a near equal ratio in terms of fetching water in which the female were slightly more involved $(53 \%, n=46)$ than the male child $(47 \%, \mathrm{n}=41)$. Guarding the home was a minor activity for the children with only four cases for the male child and two cases for the female children were involved compared to $44 \%(n=19)$ of the male children. The identified gender differences are not a surprise because the society has stereotyped activities it expects from boys and girls (Mweru, 2005).

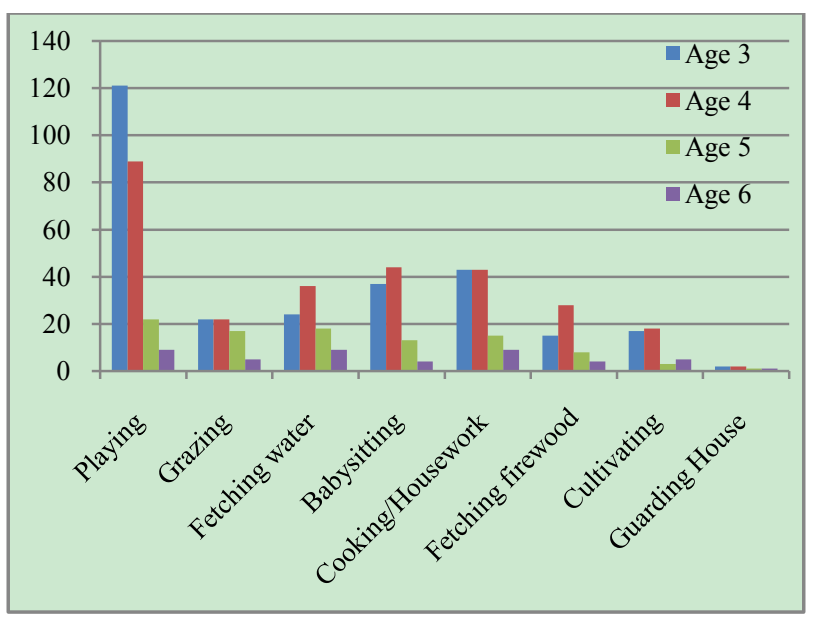

Graph 2. Children $\backslash$ s age and their activities
In terms of children's age, the analysis indicated that playing (the dominant activity) tended to be prevalent with younger children. Other activities indicated a tendency of being common among older children (graph 2). The decrease of playing activities among older children could possibly be explained by the increase in other responsibilities assigned to them by the parent/ guardian.

Playing as a daily activity of the children was mentioned by most male and female parents/ guardians $(84 \%, \mathrm{n}=241)$ aged between $20-39(81 \%, \mathrm{n}=233)$ and it still dominated irrespective of the age of parents/ guardians (Graph 3 and 4).

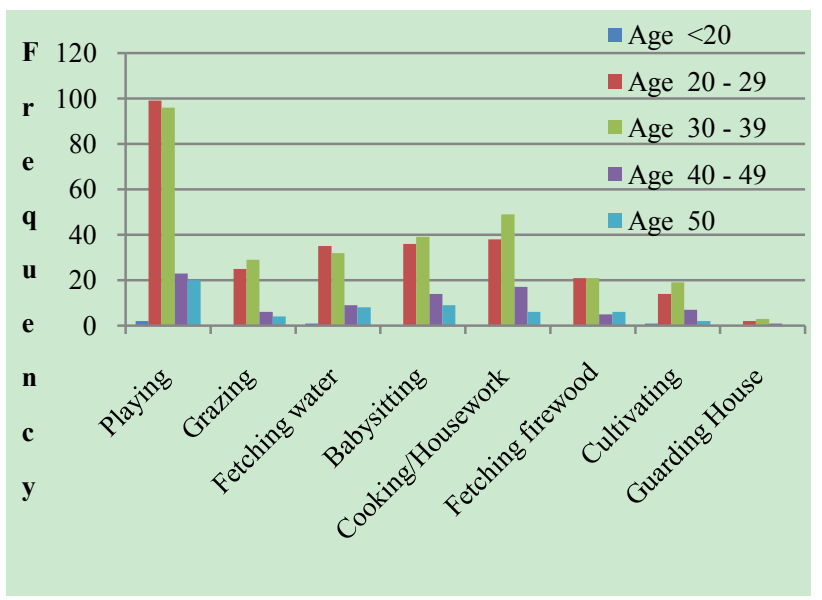

Graph 3. Age of guardian/parent by the daily activity

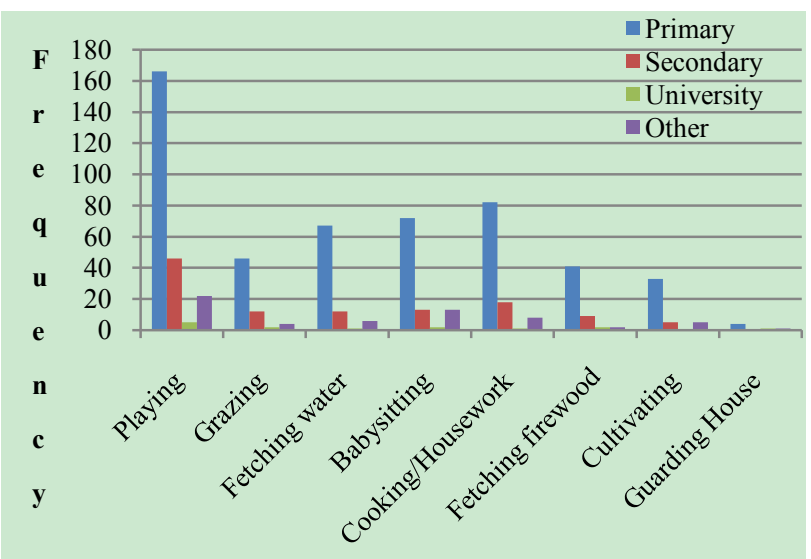

Graph 4. Academic background of guardian/parent by daily activity of child

Although the parents/ guardians accepted that playing was taking much of the children's time, they termed it as unproductive and not crucial in the child's growth and development. However, according to the parents/guardians, play distinguished children from adults. Through play children were able to emulate adult duties which the parents/ guardians expected them to grow to be responsible for. This is in agreement with Mweru's (2005) research findings which showed that children informally teach each other during their play activities. According to Vygostky (1978), play activities contribute towards children's zone of proximal development, especially through their social interactions.

It was observed that parents were not involved in their 
children's play activities and that children did not have sufficient play materials which initiate children's critical, heuristic, insightful and creative thinking skills. Moreover, as children played, they ended up in hostile episodes leading to their aggressive behavior towards one another.

For instance, older children sometimes manifested aggressive behavior as they assumed the role of adults towards the younger children whom they were left with. This raised concern in matters of children protection during play which parents seemed to take for granted. Mweru (2005) raises this same concern in her research among "children teachers" in Thika District, Kenya. She found that the younger children were often bullied by the older children during play activities. Mugo (2005) in her investigation of causes of accidents among preschool children in Westlands, Nairobi, recommends that security during children's play is an issue which requires involvement of the parents and the government.

Parents agreed that though children had to play, they also had something else to do for the wellbeing and survival of the society. Other common children's activities were cooking, baby sitting, fetching water, grazing, fetching firewood and cultivating (Figure 1). These children's activities seemed to be the expected trend within the rural setup where children as members of the community had transitional roles to play. Apart from play, they had a responsibility to participate in the community life. In this context, children were playing a key role as a human resource to sustain their society by contributing towards the social economic set up of the society. For instance, they provided care and informal education to their young siblings through babysitting as their parents/guardians pursued other duties. However, what these children were doing was at the expense of their formal education. This implies that they were being denied the crucial preparation for primary schooling. Despite the children's assistance to their parents, the family's poverty level still remained high. Yet, even the free compulsory primary education expected parents/ guardians to be financially committed in certain respects (like buying uniform) to ensure their children were registered in primary schools (Abagi, 1997).

The respondents (parents/ guardians) were required to explain why these 287 children were not in school and what the future plans for them were. Most guardians/ parents $(97 \%$, $\mathrm{n}=278$ ) indicated that it was their intention to give their children education. They gave three main reasons why their children were not in preschool. These reasons were that they regarded their children as underage $(48 \%, \mathrm{n}=137)$, lack of fees $(28 \%, \mathrm{n}=80)$, and the long distance from their residence to the preschool $(12 \%, \mathrm{n}=35)$.

The three to six children's readiness for school has to be taken in the context of what parents viewed schooling to be. They preferred schooling to start at age seven as advocated and implemented by the Government (Republic of Kenya, 2005). Anything earlier than six was not in the parents/ guardians' planning and budgeting on account of their low economic empowerment. The essence of the worth of preschool education in the preparation of primary schooling was not clear to these 287 parents/ guardians of Machakos District. Sessional Paper No. 1, 2005 focuses on this lack of knowledge which contributes towards the $65 \%$ of Kenyan children not being in preschool. According to Swadener and Kabiru (1995), age, gender and the social geographical region should not be factors to deny any child his/her education which is one's basic right. Furthermore, it is wrong for the parents/guardians to assume that their children are not ready for education. By age two, all thinking structures needed for a child to learn are ready (Colletta et al., 1996). It is evident that the education for three to six year old children has a lot of impact on their future undertaking of schooling and societal responsibilities.

The fees concern is reinforced by parents/guardians advocating for free preschool education $(39 \%, \mathrm{n}=113)$, Government constructing more preschools $(13 \%, \mathrm{n}=37)$ and training more preschool teachers $(8 \%, \mathrm{n}=24)$. This has to be understood in the context that parents and local communities are expected to manage and maintain their preschools and pay the preschool teachers (Republic of Kenya, 2005). To a community like Machakos which has limited resources, this may not be realized. In fact, most of the participants were subsistence farmers $(69 \%, \mathrm{n}=198)$ and local business traders $(15 \%, n=42)$. These are activities basically geared towards subsistence living and survival. Thus, poverty may be the hindrance to the 287 children not accessing preschool. This is in agreement with Garcia and Lukshin (2001) who found that poverty may hinder some children from receiving their education. However, the 1989 Convention stipulated that "all children" have the right to education (UNESCO, 2005), and it makes no concession to poverty as a condition that may curtail that right.

\section{Recommendations}

Parents/guardians are the natural minders of children. Through local non - governmental organizations, constituency development committees, local religious groups and local adult educational centres, there is need to advocate and lobby for parental/guardian education programmes which would empower parents to be committed and responsible towards their children's education. These programmes would focus on basic issues pertaining to child growth and development and children's basic rights. The programmes would be alternatives to preschool education and will invigorate early Childhood Education.

They would be similar to what has happened in Turkey through parental educational programmes. The mother child education in Turkey is an example of a parental educational approach that has benefited the child, the mother and the community ( Kagitcibasi, et al., 1995). The programme, derived from Home Instruction for parents of Preschool Youngsters (HIPPY) of Israel, targeted preschool age children who were in difficult circumstances and the parents who needed financial empowerment. Using principles and practice of adult education and child development, a cost 
effective programme was established which provides an alternative to the regular preschool system of education which Myres (1995) refers to as multipurpose in nature as it integrates family life, mother/ child care, nutrition and preparation for the child's schooling. In fact, van Oudenhoven (2003) and Myres (1995), stressing on the importance of the parents' education, indicate than even when parents do not have much to give, they still provide something basic and essential to their children.

The Kenyan Government has to fulfill its 1989 Convention promises in the context preschool education crucial and by facilitating all Kenyan children to receive it. Preschool education can be free and compulsory for all three to six year old children.

Research needs to be undertaken to better understand children's activities in the context of cultural diversity in Kenya. It is necessary to investigate parental involvement in children's play activities. This can be done by focusing on how play leads to children's critical, creative, heuristic and insightful skills.

\section{Conclusions}

In spite of the limited scope of the present study, the findings indicate that the right to education and play of the three to six year old children not in preschool is not being taken seriously by parents and the government. These findings are important to both parents, Counseling Psychologists and the government who need to commit themselves to all children's education, play and to the eradication of poverty that undermines children's full growth and development. This commitment will guarantee children more dignified lives.

\section{REFERENCES}

[1] Abagi, O. (1997) Public and Private Investment Education in Kenya: An Agenda for Action. Nairobi: The Legal Press Kenya, Ltd.

[2] Colletta, N.J, et al.. (1996) The Condition of Young Children in Sub - Saharan Africa. Washington, D.C.: The World Bank.

[3] Edwards, M. (1996) "Policy Arena. Children in Developing Countries. New Approaches to Children and Development: Introduction and Overview." Journal of International Development, Vol. 8, No. 6, pp. $813-827$.
[4] Garcia, M. \& M. Lukshin (2001) "Impact of Early Childhood Development Programs on Women's Labour Force Participation and Older Children's Schooling in Kenya." In: A Directory of Early Childhood Development Projects in Africa. Washington: World Bank, pp. $60-62$.

[5] Kagitcibasi, C. et al.. (1995) "A Multipurpose Model on Non formal Education: The Mother Child Education Programme, "In: The Consultative Group on Early Childhood Care and Development, No. 17, pp. 1 - 11.

[6] Mugo, J.W. (2005) "Report of Causes of Accidents among Preschool Children in Westlands Division of Nairobi, Kenya." M.Ed. Thesis, Kenyatta University, Kenya.

[7] Mweru, M. (2005) Sibling Teaching among the Agikuyu of Kenya. Marburg: Tectum Verlag.

[8] Myers, R.G. (1995). The Twelve who Survive:. Strengthening Programmes of Early Childhood Development in the Third World. London, New York: Routledge.

[9] Republic of Kenya (1997) Mbeere Development Plan 1997 2001. Nairobi: Government Printer.

[10] (2005) Sessional Paper No. 1, 2005. A Policy Framework for Education, Training and Research. Meeting the Challenges of Education, Training and Research in Kenya in the $21^{\text {st }}$ Century. Nairobi: Government Printer.

[11] (2002) The Children Act 2001. In: Kenya Gazette Supplement: Acts 2001. Nairobi: Government Printer, pp.493 - 680.

[12] Swadener, B.B. \% M. Kabiru (1995) "Does the Village still Raise the Child?" A Collaborative Study of Changing Child Rearing and Community Mobilization in Kenya. Kent State University and Nairobi: NACECE.

[13] UNESCO (1990) World Conference on Education For All. Meeting Basic Learning Needs. Jomtien, Thailand, 5 - 9 March 1990. Paris: UNESCO.

[14] (2000) The World Education Forum. Dakar, Senegal, 26 - 28 April 2000. Paris: UNESCO.

[15] (2005) "Early Childhood and Family Policy Series. Policy Review Report: Early Childhood Care and Education in Kenya." Paris: UNESCO.

[16] United Nations. (1996 - 2002) Convention on the Rights of the Child. Geneva: Office of UN.

[17] Van OUdenhoven, N. (2003) "Early Childhood Development in Global Policy Perspectives." In: K. Broekhof (ed), Ethnic and [18] Cultural Minorities in Education. Utrecht: Sardes European Accession Series. Vol. 3, pp. $41-58$.

[18] Vygostky, L.S. (1978) Mind in Society: The Development of Higher Mental Processes. Cambridge, M.A.: Harvard University Press. 